\title{
Retinal Degeneration in Transgenic Mice with Photoreceptor- Specific Expression of a Dominant-Negative Fibroblast Growth Factor Receptor
}

\author{
Peter A. Campochiaro, ${ }^{1,2}$ Michelle Chang, ${ }^{1}$ Masahiko Ohsato, ${ }^{1}$ Stanley A. Vinores, ${ }^{1}$ Zuquin Nie, ${ }^{1}$ \\ Leonard Hjelmeland, ${ }^{3}$ Alka Mansukhani, ${ }_{4}^{4}$ Claudio Basilico, ${ }^{4}$ and Donald J. Zack ${ }^{1,2,5}$ \\ 1The Wilmer Ophthalmological Institute, ${ }^{2}$ Departments of Neuroscience and 5 Molecular Biology and Genetics, The Johns \\ Hopkins University, Baltimore, Maryland 21287-9277, 3Departments of Ophthalmology, Molecular and Cell Biology, and \\ Biological Chemistry, University of California, Davis, California 95616-8635, and ${ }^{4}$ Department of Microbiology and \\ Kaplan Cancer Center, New York University School of Medicine, New York, New York 10016
}

Mutant cDNAs coding for dominant-negative forms of the fibroblast growth factor receptors 1 (FGFR-1) and 2 (FGFR-2) that lack tyrosine kinase activity were ligated to a $2.2 \mathrm{~kb}$ DNA fragment containing the bovine rhodopsin promoter and used to generate transgenic mice. Six independent lines were generated with the FGFR-1 construct, and five were generated with the FGFR-2 construct. Five of the six FGFR-1 mutant lines and all five FGFR-2 mutant lines showed transgene expression in the retina by reverse transcription-PCR. By both in situ hybridization and immunohistochemistry, mutant FGFRs were found to be expressed specifically in photoreceptors of transgenepositive FGFR-1 and FGFR-2 mice. Lines expressing the FGFR-2 mutant showed progressive photoreceptor degeneration; the retinas showed minimal or no abnormalities at 1 month, but by 2 months they showed focal areas of thinning of the outer nuclear layer and disruption of photoreceptors. By 2-4 months, areas of complete loss of photoreceptors were seen. These abnormalities were not seen in control littermates not expressing the transgene. Mice from two FGFR-1 mutant lines showed focal areas of thinning of the outer nuclear layer and numerous photoreceptors with fragmented chromatin, whereas the other FGFR-1 lines showed minimal or no abnormalities. These data indicate that perturbation of FGF signaling in photoreceptors is associated with progressive photoreceptor degeneration, suggesting that one or more of the FGFs may act as a survival factor for photoreceptor cells.

Key words: photoreceptors; retinal degeneration; fibroblast growth factors; fibroblast growth factor receptors; dominantnegative mutation; trophic factors; rhodopsin promoter
In 1921, Ramon y Cajal suggested the possibility that neurons require substances from their surrounding environment to maintain viability (Ramon y Cajal, 1921). Since then, a great deal of experimental evidence has been generated in support of this hypothesis, and it is now widely accepted that most neurons require trophic support. In the retina, a number of growth factors, neurotrophins, and related signaling molecules have been implicated in the regulation of the development and maintenance of structure and function. Among those factors implicated are members of the fibroblast growth factor (FGF) family. Acidic FGF, basic FGF, and FGF-5 have been demonstrated in both the retina and retinal pigmented epithelium (RPE) (Schweigerer et al., 1987; Baudouin et al., 1990; Connolly et al., 1992; Gao and Hollyfield, 1992; Raymond et al., 1992; Kitaoka et al., 1994). Basic and acidic FGFs promote the expression of differentiation markers in photoreceptors and RPE in vitro (Hicks and Courtois, 1992; Campochiaro and Hackett, 1993), and they also influence retinal progenitor cell fate determination (Guillemot and Cepko, 1992). Addition of basic or acidic FGF to embryonic chick eye cups

Received July 25, 1995; revised Dec. 11, 1995; accepted Dec. 14, 1995

This research was supported by Public Health Service Grants EYO5951, EY09769, and EY10017; National Eye Institute Core Grant P30 EYO1765; a grant from The Foundation Fighting Blindness; and unrestricted funds from Research to Prevent Blindness.

Correspondence should be addressed to Peter A. Campochiaro, 719 Maumenee, The Wilmer Ophthalmological Institute, The Johns Hopkins Hospital, 600 North Wolfe Street, Baltimore, MD 21287-9277.

Copyright (C) 1996 Society for Neuroscience $0270-6474 / 96 / 161679-10 \$ 05.00 / 0$ causes regeneration of neural retina from the RPE (Park and Hollenberg, 1989; Pittack et al., 1991). It has also been suggested that the FGFs play a role in retinal abnormalities such as neovascularization (for review, see D'Amore, 1994).

Recently, attention has been focused on possible neurotrophic effects of the FGFs in the retina. Basic FGF promotes photoreceptor survival in Royal College of Surgeons rats with an inherited retinal dystrophy (Faktorovich et al., 1990), and both basic and acidic FGFs decrease photoreceptor cell death when injected into the vitreous of rats before expusure to constant light (LaVail et al., 1992). These studies suggest that one or more of the FGFs might naturally act as survival factors in the outer retina. One way to test this hypothesis is to block FGF signal transduction in vivo. Knockout of the various FGF genes offers an approach to eliminate individual FGFs. Such knockouts, however, may be lethal because of the important and varied roles of the FGFs in development. Furthermore, even if FGF knockouts were not lethal, the expression of multiple FGFs in the retina raises the possibility that redundancy of function might obscure the effects of eliminating a single FGF.

Another approach to studying the role of the FGFs in the retina is to perturb the function of FGF receptors (FGFRs). There are four FGFR genes currently referred to as FGFR-1 ( $f l g)$, FGFR-2 (bek), FGFR-3, and FGFR-4 (for review, see Johnson and Williams, 1993). The proteins coded by the four human receptor genes are very similar, with a level of homology (72\% amino acid identity) greater than that seen among the members of the FGF 
family. There are multiple forms of FGFR-1 and FGFR-2 attributable to alternative splicing of their mRNAs. Both alternative splicing of mRNAs and sequence differences among the receptor genes may contribute to signaling specificity. Photoreceptors and RPE cells express FGFR-1 and FGFR-2 (Ohuchi et al., 1994; Tcheng et al., 1994). As is the case with the FGFs, gene knockouts of the FGFRs is not a viable method for studying FGF function specifically in the retina. Disruption of the FGFR-1 gene results in several developmental abnormalities and embryonic death (Deng et al., 1994; Yamaguchi et al., 1994), and it is likely that disruption of the FGFR-2 gene would have similar consequences.

An alternative approach is to use dominant-negative receptor mutations that lack a functional ligand-induced tyrosine kinase domain (Amaya et al., 1991; Ueno et al., 1991, 1992). Because tyrosine kinase receptors require dimerization for normal signaling, expression of a defective receptor can interfere with the function of wild-type receptors and eliminate the ability of a cell to respond to the ligand. Expression of an FGFR with a tyrosine kinase domain deletion in Xenopus embryos interferes with FGFR signaling and disrupts mesoderm development (Amaya et al., 1991). Coupling a mutated FGFR gene to a tissue-specific promoter avoids disruption of FGF signaling in other tissues and provides a means to investigate the role of FGFs in a single cell type. Targeted expression of an FGFR mutant in suprabasal keratinocytes using the keratin 10 promoter has been used to demonstrate that FGFs play an essential role in keratinocyte organization and differentiation (Werner et al., 1993). In a similar manner, the surfactant protein $C$ promoter was used to achieve specific expression of an FGFR mutant in lung bud epithelium and demonstrated a specific role for FGFs in branching morphogenesis and epithelial differentiation of the mammalian lung (Peters et al., 1994).

Here we have used a similar strategy to study the role of FGFs in retinal photoreceptors. We have coupled the bovine rhodopsin promoter to FGFR-1 and FGFR-2 genes with deleted tyrosine kinase domains and have gencrated transgenic mice that demonstrate photoreceptor-specific expression of the dominant-negative FGFR mutants. Our results indicate that FGFR-mediated signaling is necessary for photoreceptor survival.

\section{MATERIALS AND METHODS}

Generation of transgenic animals. The $2.2 \mathrm{~kb}$ HindIII/NaeI fragment that contains the bovine rhodopsin promoter (Zack et al., 1991) was cloned upstream of the mutant murine FGFR-1/ and FGFR-2/rabbit $\beta$-globin fusion genes ( $\mathrm{Li}$ et al., 1994); after transformation, clones with correct orientations were selected. DNA was purified twice using $\mathrm{CsCl}$ and cut with HindIII and $E c o$ RI to provide a $3.4 \mathrm{~kb}$ rhodopsin promoter/mutant FGFR-1/ $\beta$-globin fusion gene and a $4.2 \mathrm{~kb}$ rhodopsin promoter $/$ mutant FGFR-2/ $\beta$-globin fusion gene. The fusion genes were purified and transgenic mice were generated using established techniques as described previously (I Iogan et al., 1986; Zack et al., 1991). The FGFR-1 construct

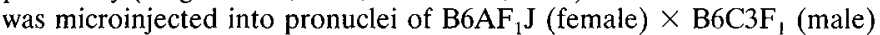
embryos, and the FGFR-2 construct was microinjected into pronuclei of $\mathrm{B} 6 \mathrm{AF}_{1}$ (female) $\times \mathrm{C} 57 \mathrm{BL} / 6 \mathrm{~J}$ (male) embryos. All offspring were backcrossed to C57BL/6J mice. Because some of the FGFR-1 offspring could have been heterozygous for the mutant $r d$ allele, which causes photoreceptor degeneration, all offspring were screened by PCR for the mutant allele (Pittler and Baehr, 1991). The few animals that were found to carry the $r d$ mutation were killed. None of the mice used for analysis carried the mutant $r d$ allele.

Mice were screened for the presence of the transgene as described previously (Zack et al., 1991). After a "hot start" at $94^{\circ} \mathrm{C}$ for $5 \mathrm{~min}, 35$ cycles of amplification were carried out with the following protocol: $94^{\circ} \mathrm{C}$ for $1 \mathrm{~min}, 56^{\circ} \mathrm{C}$ for $30 \mathrm{sec}$, and $72^{\circ}$ for $30 \mathrm{sec}$ with flg forward (P1: GTAACAGTGTCAGCTGACTC) or bek forward (P3: GCTCCTCCATGAACTCCAAC) and globin-1 primers (P4: AAGAGGAGACAATG-
GTTGTC). Reaction products were analyzed by agarose gel electrophoresis.

Retinal reverse transcription (RT)-PCR. RNA was isolated from the retinas of 1-month-old mice using the guanidine isothiocyanate method as described by (homczynski and Sacchi (1987). RT was carried out with $\sim 0.5 \mu \mathrm{g}$ of RNA, reverse transcriptase (Gibco, Gaithersburg, MD), and $3.5 \mu \mathrm{M}$ oligo $\mathrm{d}(\mathrm{T})$ primer. Aliquots of the cDNAs were used for PCR amplification with the flg forward (P1), bek forward (P3), and globin-2 (P2: AGCCACCACCTTCTGATAGG) primers as described above. These primers amplify across an intron-exon border. The expected PCR products for the FGFR-1 transgene from DNA and mRNA are $305 \mathrm{bp}$ and $213 \mathrm{bp}$, respectively; the expected PCR products for the FGFR-2 transgene from DN $\Lambda$ and $m R N \Lambda$ are $288 \mathrm{bp}$ and $197 \mathrm{bp}$, respectively. Titrations were performed to insure that PCR reactions were carried out in the linear range of amplification. Mouse S16 ribosomal protein primers (CACTGCAAACGGGGAAATGG and TGAGATGGACTGTCGGATGG) were used to provide an internal control for the amount of template in the PCR reactions (Wagner and Perry, 1985).

In situ hybridization. In situ hybridization with digoxigenin-labeled sense and antisense probes for $f l g$ or bek and rabbit $\beta$-globin was used to localize transgene expression in the retina, using a procedure that was published previously (Campochiaro et al., 1994). To prepare rabbit $\beta$-globin probes specific for the transgenes, an RT-PCR-derived $109 \mathrm{bp}$ fragment of rabbit $\beta$-globin cDNA including the exon2/exon3 junction was subcloned into pCR-Script SK (Stratagene, La Jolla, CA). The PCR product was blunt-ended with T4 DNA polymerase (New England Biolabs, Beverly, $\mathrm{M} \Lambda$ ) and digested with $\mathrm{Bam} \mathrm{HI}$ to remove $5^{\prime} \mathrm{flg}$ sequences. The insert was then ligated into EcoRV- and BamHI-digested vector. Clones were verified by sequencing.

Immunohistochemistry. Immunohistochemistry was carried out on $8 \mu \mathrm{m}$ frozen sections of retina from transgene-positive and control mice, using previously published techniques (Campochiaro et al., 1994). A rabbit polyclonal anti-FGFR-1 antibody (Upstate Biotechnology, Lake Placid, NY) was used in a 1:25 dilution, and a rabbit polyclonal anti-FGFR-2 antibody (generously provided by Irit Lax, Ph.D., Department of Pharmacology, New York University School of Medicine) was used in a 1:100 dilution. For controls, normal rabbit serum was substituted for the primary antibodies. The chromogen was HistoMark Blue (Kirkegaard and Perry, Gaithersburg, MD), which was developed according to the instructions of the manufacturer. Slides were photographed on a Zeiss Axioskop microscope using Nomarski optics with Kodak 64T tungsten film.

Evaluation of retinas by light and electron microscopy. Mice were killed at the appropriate time points by cervical dislocation or by cardiac perfusion, first with lactated Ringer's solution and then with $4 \%$ paraformaldehyde in $0.05 \mathrm{M}$ phosphate buffer, $\mathrm{pH} 7.4$, after being anesthetized with a mixture of xylazine hydrochloride and ketamine hydrochloride. The corneas of nonperfused mice were removed, and the eyes of both perfused and nonperfused mice were then immersed in $2 \%$ paraformaldehyde $2 \%$ glutaraldehyde in $0.1 \mathrm{M}$ cacodylate buffer, $\mathrm{pH} 7.4$, at $4^{\circ} \mathrm{C}$ and stored in this solution. Eyes were bisected along the midline through the cornea and the optic disk and strips of retina with attached choroid and sclera were cut adjacent and parallel to the cut surface. The retinal strips were osmicated, dehydrated, and embedded in Poly/Bed 812 (Polysciences, Warrington, PA) as described previously (Vinores ct al., 1988). The tissue was sectioned, counterstained with uranyl acetate and lead citrate, and viewed with a JEOL $100 \mathrm{CX}$ electron microscope at an accelerating voltage of $60 \mathrm{kV}$. Micrographs were taken on Kodak 4489 electron image film.

\section{RESULTS}

\section{Expression of dominant-negative FGFRs in the photoreceptors of transgenic mice}

Murine cDNAs for truncated FGFR-1 and FGFR-2 that contain the coding region for the entire extracellular domain, the transmembrane region, and the first 32 and 74 amino acid residues, respectively, of the intracellular domain have been described previously (Li et al., 1994). The cDNAs for each truncated receplor were ligated to the $2.2 \mathrm{~kb} H$ HindII/NaeI bovine rhodopsin upstream fragment, which contains the rhodopsin enhancer region and the proximal promoter region (Zack et al., 1991; Nie et al., 1996) (Fig. 1). The resulting fusion genes were used to gen- 

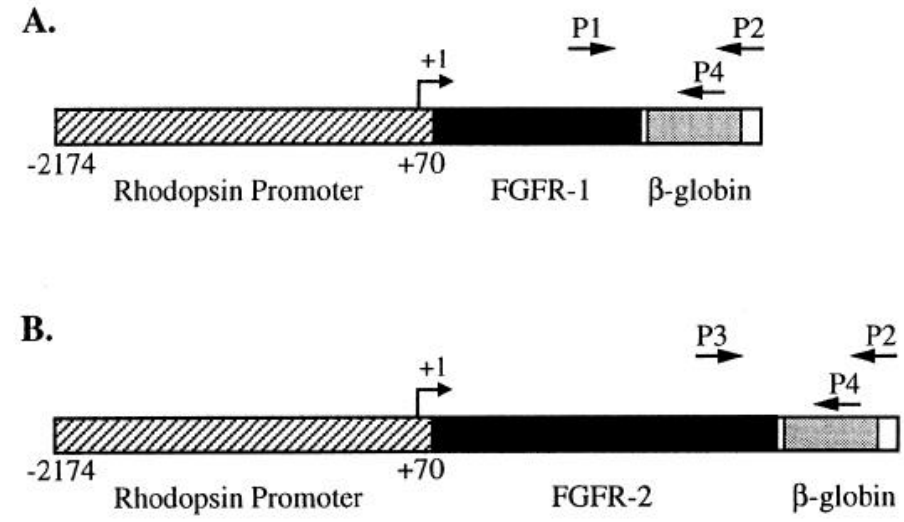

Figure 1. Schematic map of the rhodopsin promoter/FGFR-1 and rhodopsin promoter/FGFR-2 fusion genes. The $2.2 \mathrm{~kb}$ HindIII/NaeI DNA fragment containing the bovine rhodopsin promoter and rhodopsin enhancer region was cloned upstream of mutant FGFR-1/ and FGFR-2/ rabbit $\beta$-globin fusion genes. The FGFR- 1 and FGFR- 2 mutants contain the coding region for the extracellular domain, the transmembrane region, and the first 32 and 74 amino acid residues, respectively, of the intracellular domain. The $1.7 \mathrm{~kb} \beta$-globin sequence, which is located in the $3^{\prime}$-untranslated region, contains part of exon 2 , intron 2 , and exon 3 , so as to provide an intron and poly $\mathrm{A}$ addition site to increase transgene expression. The position of primers $P 1-P 4$, which were used in PCR analysis, is indicated.

erate transgenic mice. Six independent lines that incorporated the mutated FGFR-1 (designated flg-3, -12, -13, -23, -27, and -46) and five that incorporated the mutated FGFR-2 (designated bek-1, -6, $-9,-18$, and -56 ) were obtained.

Total RNA was isolated from the retinas of several transgenepositive mice from each line, and expression of transgene mRNA

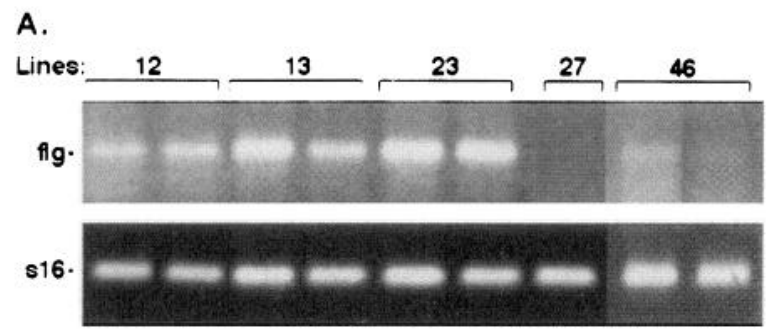

B.

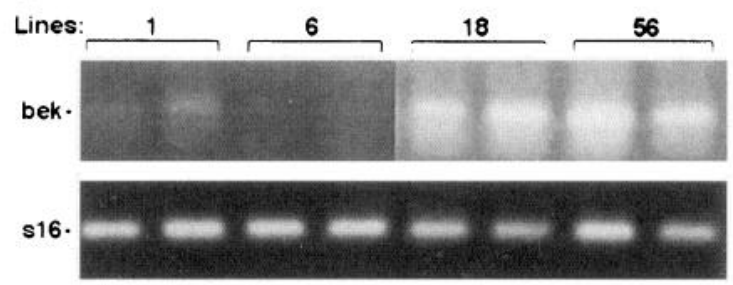

Figure 2. Transgene expression in the retinas of transgenic mice by RT-PCR. Total RNA and cDNA were prepared from the retinas of $f l g$ and bek transgenic mice, and 20 cycles of PCR amplification were performed using primer pairs $\mathrm{P} 1$ and $\mathrm{P} 2$ or $\mathrm{P} 2$ and $\mathrm{P} 3$ for $f l g(A)$ and bek $(B)$, respectively, and analyzed by agarose gel electrophoresis. PCR was also carried out with primers for ribosomal protein S16 as a control for the amount of template cDNA. Ethidium bromide-stained gels were scanned with an AGFA (Mortsel, Belgium) Arcus Plus flat-bed scanner, a composite of representative samples showing reaction products from two independent animals from each line was assembled with Photoshop 3.0 (Adobe, Mountain View, CA), and the image was printed with a Kodak (Rochester, NY) XL 7700 Digital Continuous Tone printer. was assessed by semiquantitative RT-PCR using oligonucleotide primers specific for each construct (Figs. 1, 2). PCR conditions were adjusted such that all reactions were performed in the linear range of amplification. PCR with primers specific for ribosomal protein S16 mRNA was also performed to control for the amount of starting RNA. The relative amount of mutant receptor mRNA expressed in the retina was consistent among mice from the same lines. Two of the FGFR-1 mutant lines, flg-13 and -23, showed relatively high levels of expression, the $f l g-12$ and -46 lines showed lower levels, and the $f l g-27$ line showed no reaction product with 20 cycles of amplification, but a distinct band was seen with 35 cycles (data not shown); the flg-3 line could not be propagated and was not tested. Two of the FGFR-2 mutant lines, bek-18 and -56, showed relatively high levels of expression, the bek-1 line showed lower levels, and no reaction product was seen for the bek-6 line at 20 cycles of amplification, but a distinct band was seen at 35 cycles (data not shown); the bek-9 line was not tested because of the difficulty in propagation of the line.

In situ hybridization was performed with digoxigenin-labeled riboprobes for FGFR-1 and FGFR-2. Retinas from the bek-1, -18, and -56 lines showed reaction product in photoreceptor cell bodies and inner segments with antisense FGFR-2 probe (Fig. 3A). No staining was seen with sense probes (Fig. $3 B$ ). Staining was not detected with either antisense or sense probes in control mice (Fig. 3D), suggesting that the sensitivity of our technique is not sufficient to detect endogenous receptor mRNA. Hybridization with an antisense probe for a portion of the rabbit $\beta$-globin sequences contained in the transgene demonstrated staining in photoreceptor cell bodies and inner segments similar to that seen with the FGFR-2 antisense probe (not shown). Hybridization with an antisense probe for murine opsin showed staining in photoreceptor inner segments that was similar in bek and control mice (Fig. $3 C, E$ ). Mice from the $f l g-12$ line showed reaction product in photoreceptor cell bodies and inner segments when hybridization was carried out with antisense FGFR-1 probes. Staining was not seen in several mice from the flg- 27 and -46 lines or in control mice (not shown).

Immunohistochemical staining with anti-FGFR-1 antibody showed reaction product limited to photoreceptors in transgenepositive flg mice (Fig. $4 A, C$ ). Staining was not detectable in transgene-negative littermates (Fig. $4 B$ ) or in control C57BL/6J mice (not shown), indicating that our immunohistochemical technique was not sufficiently sensitive to detect endogenous FGFRs. Staining with anti-FGFR-2 antibody showed reaction product limited to photoreceptors in transgene-positive bek mice (Fig. $4 D, E)$, and there was no staining in transgene-negative littermates (Fig. $4 F$ ) or in control C57BL/6J mice. Also, there was no staining on sections from PCR-positive flg or bek mice in which normal rabbit serum was substituted for the anti-FGFR-1 or anti-FGFR-2 primary antibodies, respectively (not shown). Therefore, by both in situ hybridization and immunohistochemistry, mutant FGFRs are expressed specifically in photoreceptors of transgene-positive flg and bek mice.

\section{Photoreceptor degeneration in transgenic mice expressing dominant-negative FGFRs}

Through 1 month of age, the retinas of all transgenic mice examined were minimally distinguishable, if at all, from normal mice (Fig. $5 A$ ) as assessed by both light and electron microscopy. A representative light micrograph from the retina of a 1-month-old bek-1 mouse (a line with intermediate level of transgene expression) and an electron micrograph from the retina of a 24 -d-old 

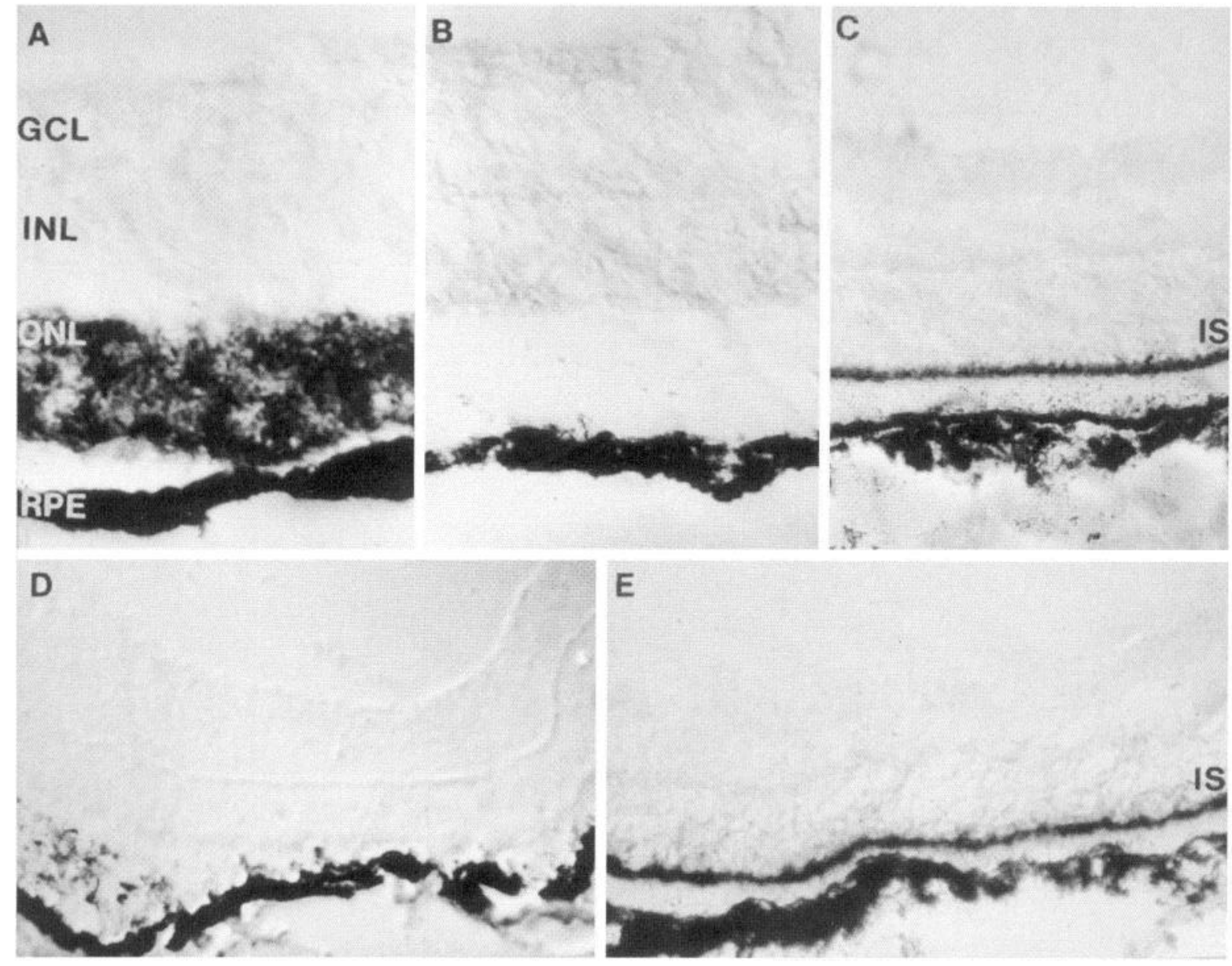

Figure 3. Localization of transgene or opsin mRNA in the retinas of transgenic and control mice. $A$, Retina from a 5-week-old bek-56 mouse hybridized with a digoxigenin-labeled antisense bek probe $(\times 250)$. The reaction product is limited to the outer layer $(O N L)$, which contains the cell bodies of photoreceptors. The inner nuclear layer $(I N L)$ and ganglion cell layer $(G C L)$ have no reaction product. The dark area at the bottom of each panel is the $R P E$ and adjacent choroid. $B$, Serial section from the same mouse shown in $A$ hybridized with a digoxigenin-labeled sense bek probe $(\times 250)$. There is no reaction product anywhere in the retina. $C$, Retina from an 8-week-old control mouse hybridized with a digoxigenin-labeled antisense opsin probe $(\times 250)$. Reaction product is limited to the inner segments $(I S)$ of the photoreceptors. The dark area at the bottom is attributable to pigment in the RPE and choroid. $D$, Retina from a 4-week-old $b e k$-1 mouse hybridized with a digoxigenin-labeled antisense bek probe $(\times 125)$. E, Retina from an 8 -week-old bek-18 mouse hybridized with a digoxigenin-labeled antisense opsin probe $(\times 125)$.

flg-12 mouse are shown (Fig. 5B,D). Figure $5 E$ shows mild ultrastructural abnormalities in a bek-1 mouse, consisting of a giant cell among slightly disorganized photoreceptor outer segments. In general, inflammatory cells were seen rarely in mutant mice and were never seen in control mice. As the mutant mice aged, evidence of retinal degeneration developed gradually. At 5 months of age, the retinas of bek-1 mice showed focal areas of photoreceptor damage and dropout (Fig. $5 \mathrm{C}$ ). Electron microscopy demonstrated that in these areas there was disruption and disorganization of photoreceptor outer segments (Fig. $5 F$ ) as well as cells with evidence of chromatin fragmentation (Fig. $5 G$ ). Figure $6 A$ shows a low-power view of the retina from a bek-1 mouse demonstrating the regional or focal nature of the photoreceptor changes. The asymmetry of the changes is seen more clearly in the high magnification views (Fig. $6 B, C$ ) corresponding to areas adjacent to the ora serrata on each side of the eye. As illustrated in Figure 6, when thinning of the outer nuclear layer was severe, mild thinning and irregularity of the inner nuclear layer was also seen.
Gradually progressive changes were also seen in the bek-6 line (a line with a low level of transgene expression). Relatively minor changes in photoreceptor outer segments were present at 3 months of age (Fig. 7A), but by 5 months focal areas with severe damage to photoreceptors and disorganization of the retina were seen. Figure $7 B$ shows an area in which the inner and outer segments have been lost and photoreceptor cell bodies abut on the RPE. Ultrastructurally, an adjacent area showed cellular debris on Bruch's membrane, with massive destruction of photoreceptors and loss of the RPE (Fig. 7C,D). In the bek-9 (unknown level of transgene expression) and -18 (high level of transgene expression) lines, some mice showed focal areas of severe photoreceptor degeneration at 2 months of age (Fig. $7 E-G$ ). These areas showed ultrastructural characteristics similar to those seen in areas of degeneration in the other lines of bek mice at later time points; the photoreceptor outer and inner segments were destroyed and replaced by debris (Fig. $7 F, G$ ). In association with photoreceptor degeneration, some areas showed blood vessels invading the RPE (Fig. $7 F$ ), which is found in animals with 

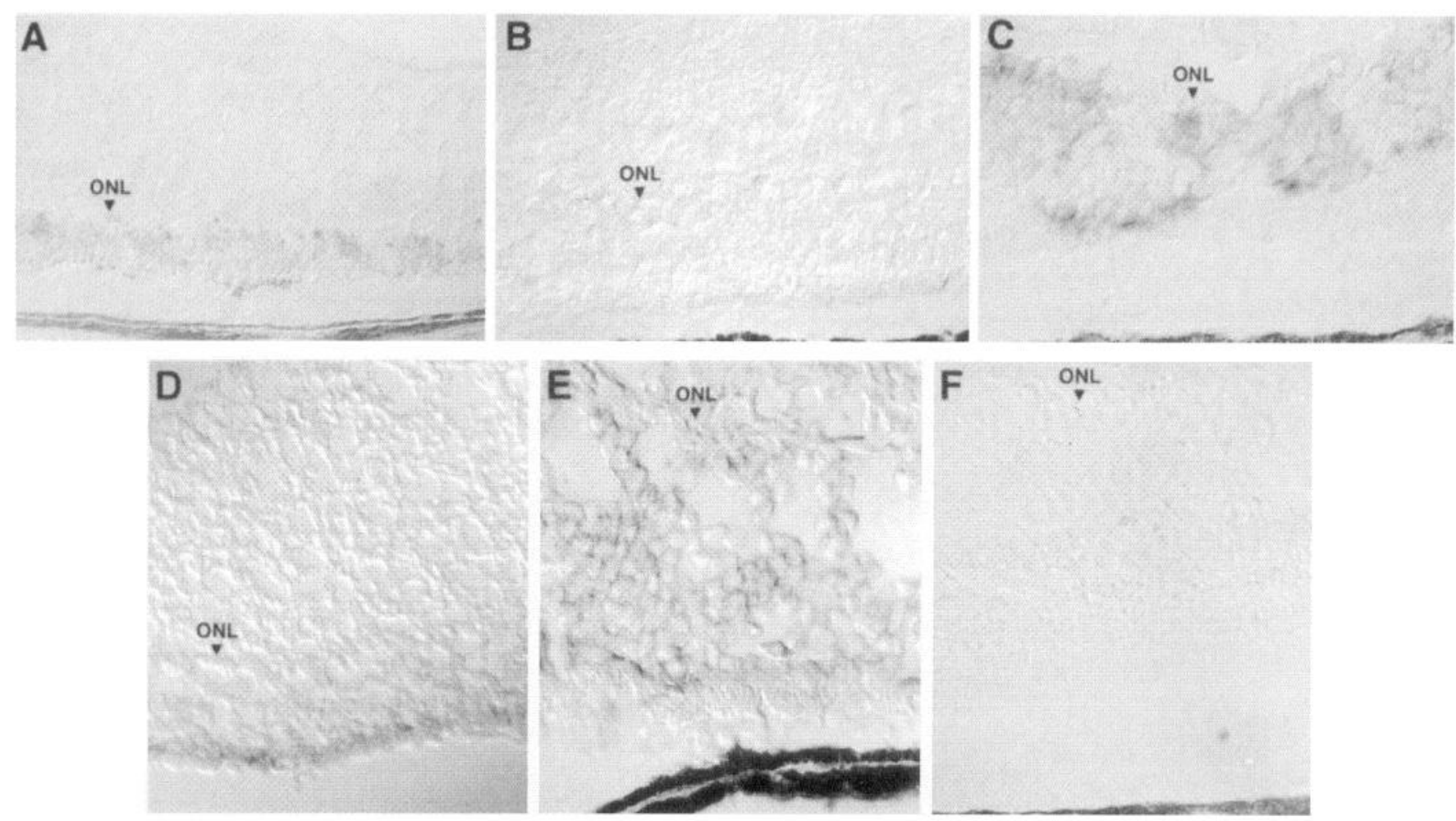

Figure 4. Localization of mutant FGFR protein in the retinas of transgenic mice by immunohistochemistry. $A$, Immunohistochemical staining with anti-FGFR-1 antibody demonstrates reaction product limited to the outer nuclear layer $(O N L)$ in a transgene-positive flg-46 mouse. $B$, A littermate control flg-46 mouse that was PCR-negative, and therefore had not incorporated the transgene, shows no staining in the $O N L$ or elsewhere in the retina with the anti-FGFR-1 antibody. $C$, A high-power view of the $O N L$ in a PCR-positive $f l g-46$ mouse shows focal staining of photoreceptors in the ONL. $D$, A PCR-positive bek-56 mouse stained with anti-FGFR-2 antibody shows reaction product limited to cells of the $O N L$. There is artifactual separation of photoreceptors from the RPE, which is not shown. $E$, A high-power view of the $O N L$ in a transgene-positive bek-56 mouse shows reaction product in photoreceptor inner segments and in some cells of the $O N L . F$, A high-power view of the $O N L$ in a PCR-negative bek-56 mouse shows no reaction product in the retina. There is artifactual separation of the photoreceptors from the RPE.

photoreceptor degeneration from inherited retinal dystrophies (Burns and Tyler, 1990). Control mice, including littermates that did not incorporate the transgene, were examined at several time points up to 6 months of age and did not show any evidence of photoreceptor degeneration.

The flg mice showed less evidence of photoreceptor degeneration than did the bek mice. When changes were noted, however, they were similar, although less severe than those seen in bek mice, and they consisted of regional thinning of the outer nuclear layer (Fig. $8 A$ ), dying or dead cells in the outer nuclear layer with evidence of chromatin fragmentation (Fig. $8 B$ ), and mild disorganization of the outer segments (not shown). A total of 36 bek mice were examined, and 18 of them showed retinal degeneration. The majority of these occurred in three lines ( 6 of 7 bek-1, 3 of 4 bek-9, and 6 of 9 bek-56). Only 6 of $31 \mathrm{flg}$ mice that were examined showed any signs of retinal degeneration.

\section{DISCUSSION}

We have tested directly the hypothesis that FGFR-mediated signal transduction is involved in the maintenance of normal photoreceptor cell structure and function. This was accomplished by using the rhodopsin promoter to target the expression of dominant-negative mutants of the FGFR to photoreceptors. Light and electron microscopic examination of retinas from mice from four independent transgenic lines that express a mutant FGFR-2 that lacks the tyrosine kinase domain demonstrated progressive photoreceptor degeneration. In each of the lines, the retinas from 1-month-old mice were essentially normal, but retinas from older mice ranging from 2 to 6 months of age showed varying degrees of photoreceptor damage. In two of the lines, definite focal photoreceptor degeneration was present by 2 months, and the degeneration became more widespread and severe as the animals aged. In two other lines, which had lower levels of mutant FGFR-2 expression, only mild abnormalities were present until 5 months of age when focal areas of photoreceptor damage were seen. When photoreceptor degeneration was severe, thinning and irregularity of the inner nuclear layer was also seen, as has been reported with some inherited photoreceptor degenerations (Blanks and Bok, 1977) and in opsin promoter-diphtheria toxin transgenic mice (Lem et al., 1991). Other pathological features that were similar to those reported for the inherited degenerations included areas of complete photoreceptor loss associated with vascularization of the RPE and even complete loss of the RPE (Burns and Tyler, 1990). These findings of retinal damage extending beyond the photoreceptor cell layer are consistent with the hypothesis that photoreceptors provide trophic support for neighboring cells (Lem et al., 1991). An alternative explanation is that the FGFR transgenes are expressed in retinal cells other than photoreceptors. Although this is a possibility, it seems unlikely on the basis of the in situ hybridization and immunohistochemical results with the flg and bek mice. In addition, previous studies with the same rhodopsin promoter fragment linked to lacZ demonstrated within the sensitivity of the methods employed that pro- 

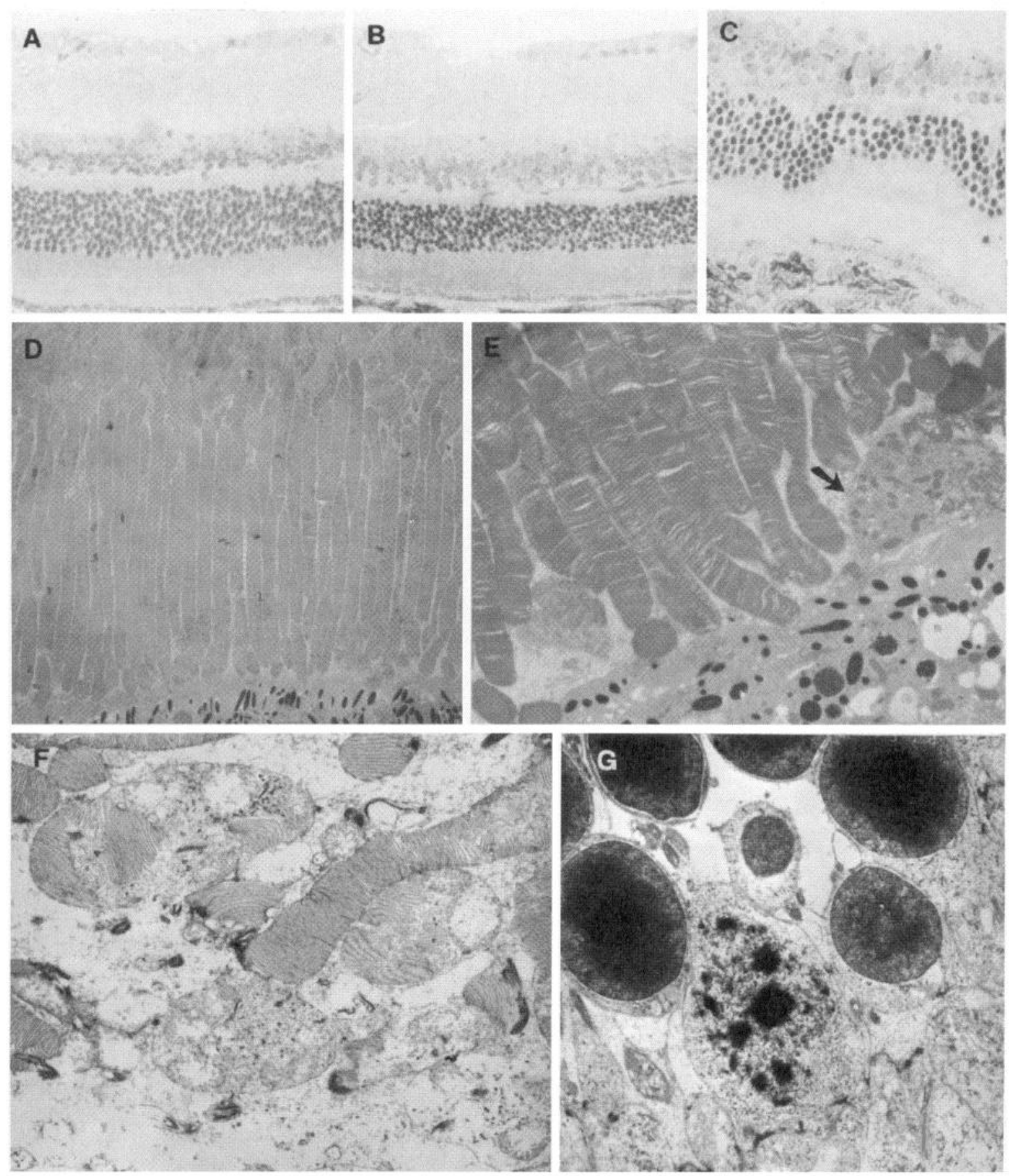

Figure 5. Slowly progressive photoreceptor degeneration in bek-1 transgenic mice. A, Normal-appearing retina from a 1-month-old control mouse $(\times 325)$. B, Normal-appearing retina from a 1-month-old bek-1 mouse $(\times 250)$. C, Retina from a 5-month-old bek-1 mouse showing only mild abnormalities at the light microscopic level; focal thinning and irregularity of the outer nuclear layer $(\times 325)$. $D$, Transmission electron microscopy shows normal outer segments in a 24-d-old flg-mouse similar to those seen in control mice and in all transgenic mice at 1 month of age $(\times 1040)$. E, A rare giant cell (arrow) seen among some slightly disorganized outer segments in a 1-month-old bek-1 mouse $(\times 4000)$. $F$, Disruption and disorganization of outer segments in a 5-month-old bek-1 mouse $(\times 6700)$. $G$, Fragmented chromatin in the nucleus of a dead cell in the outer nuclear layer of a 5-month-old bek-1 mouse ( $\times 5000) . A-C$, Stained with toluidine blue; $D-F$, stained with uranyl acetate and lead citrate.

moter activity within the retina was limited to photoreceptors (Zack et al., 1991; Gouras et al., 1994; Nie et al., 1996). It should also be noted that the same studies demonstrated that the bovine rhodopsin promoter in transgenic mice often leads to nonuniform expression across the retina, and this may account partially for the nonuniform pattern of retinal degeneration present in the flg and bek mutant mice.
Both FGFR-1 and FGFR-2 have been reported to have similar affinities for FGF-1 and FGF-2; however, the transgenic mice expressing the FGFR-1 mutant in their photoreceptors consistently demonstrated less photoreceptor damage than did comparably aged mice expressing the FGFR-2 mutant. One possible explanation is that the mutant FGFR-1 transgenes are expressed at lower levels than are the mutant FGFR-2 transgenes. The 

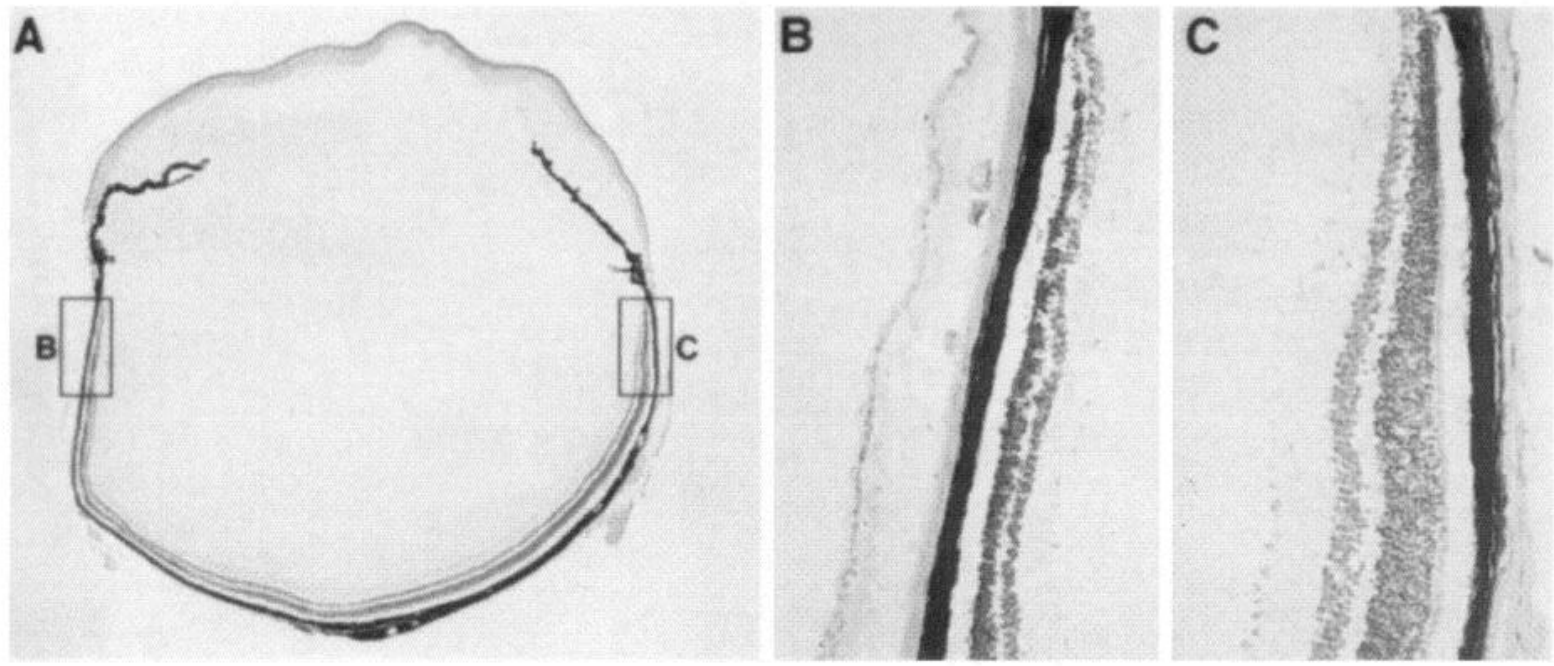

Figure 6. Regional thinning of the outer retina in a bek-1 mouse. A, Low-power view of hematoxylin and eosin-stained retinal section from an $\sim 7$-month-old bek-1 mouse. The regions enclosed in rectangles are adjacent to the ora serrata on each side of the eye and are shown at higher magnification in $B$ and $C . B$, High-magnification view of the region enclosed in rectangle $B$, demonstrating marked thinning and irregularity of the outer nuclear layer. Some thinning of the inner nuclear layer is also evident. $C$, High-magnification view of the region enclosed in rectangle $C$, demonstrating normal-appearing outer and inner nuclear layers. Photomicrographs of histological sections were digitized with a Kodak RFS 2035 film scanner, a composite was assembled using Photoshop 3.0 (Adobe), and the image was printed with a Kodak XL 7700 Digital Continuous Tone printer.

RT-PCR and immunohistochemical data argue against this possibility. Three flg lines displayed transgene mRNA levels comparable with those seen in the highest expressing bek lines, and the immunohistochemical results suggest that similar amounts of mutant FGFR protein are expressed in the flg and bek lines. Another possibility is that the FGFR-1 mutant is less effective in dimer formation and therefore less capable of disabling wild-type receptor. Ueno et al. (1992), however, demonstrated that truncated FGFR-1 mRNA, when injected into Xenopus eggs, interferes with FGFR-2 and FGFR-3 function as well as with FGFR-1 function. This suggests that mutant FGFR-1 is capable of dimerizing with and disabling other types of FGFR, although it is still possible that truncated FGFR-1 is less efficient than FGFR-2 in this regard and therefore may be less effective in causing photoreceptor degeneration. A third possibility, because FGFR-2 does have a higher affinity for FGF-4 than does FGFR-1 and truncated FGFR-2 is more effective than truncated FGFR-1 in reversing the transforming activity of FGF-4 on National Institutes of Health $3 \mathrm{~T} 3$ cells ( $\mathrm{Li}$ et al., 1994), is that FGF-4 is the major FGF that is necessary for photoreceptor survival.

Whatever the reason for the differences between mice expressing the mutant FGFR-1 and those expressing the mutant FGFR-2, we have demonstrated that the photoreceptor degeneration is not attributable simply to overexpression of a foreign protein in photoreceptors. Both mutants are C-terminal deletions that are highly homologous and are processed in a similar manner within cells ( $\mathrm{Li}$ et al., 1991). The relative lack of photoreceptor degeneration in flg mice, despite high levels of transgene expression, suggests that overexpression of FGFR is not inherently toxic to photoreceptors. Therefore, the degeneration in bek mice is likely to be related to the ability of the mutant FGFR-2 to block FGF signaling and not to some nonspecific effect.

The mechanisms by which photoreceptors die in the FGFR mutant mice and by which FGF signaling promotes photoreceptor survival are unknown. One possibility is that FGF signaling prevents activation of a default apoptotic cell death program (Manjo and Joris, 1995). Another possibility is that FGF signaling provides protection from environmental factors that are damaging to photoreceptors, which might explain the gradual progression of photoreceptor damage seen in the transgenic mice. This hypothesis is consistent with the observations that exogenous basic and acidic FGFs and optic nerve injury, which increases basic FGF expression in photoreceptors (Kostyk et al., 1994), protect photoreceptors from the damaging effects of constant light (Bush and Williams, 1991; La Vail et al., 1992). It is also consistent with observations that basic FGF has a protective effect on lesioned cholinergic neurons in the central nervous system (Anderson et al., 1988). Basic FGF protects neurons of the central nervous system against ischemia (Yamada et al., 1994) and neurotoxins such as NMDA (Freese et al., 1992), $\beta$ amyloid peptide (Mattson et al., 1993), 1-methyl-4-phenyl-1,2,3,6-tetrahydropyridine (Otto and Unsicker, 1990), and nitric oxide (Maiese et al., 1993). Our data suggest that these effects are not simply pharmacological effects of exogenous basic FGF, but they may also be an important function of endogenous FGFs. Studies are planned to determine whether the flg and bek mice are more sensitive to the damaging effects of constant light.

The findings that photoreceptors seem to develop normally in the mutant $f l g$ and bek mice and that significant retinal degeneration does not occur until after 1 month of age should not be interpreted as suggesting that FGFR-mediated signal transduction plays only a maintenance function and is not important for photoreceptor development. Because the transgenic rhodopsin promoter does not show detectable activity until approximately postnatal day 4-8 (Lem et al., 1991; Zack et al., 1991; Nie et al., 1996) and accumulation of the required levels of mutant receptor protein takes time, it is likely that inhibition of signal transduction was not achieved until well after the completion of photoreceptor differentiation. Future experiments using photoreceptor-specific promoters that are active earlier in development will be required to determine the role of FGFR-mediated signal transduction in photoreceptor development. 

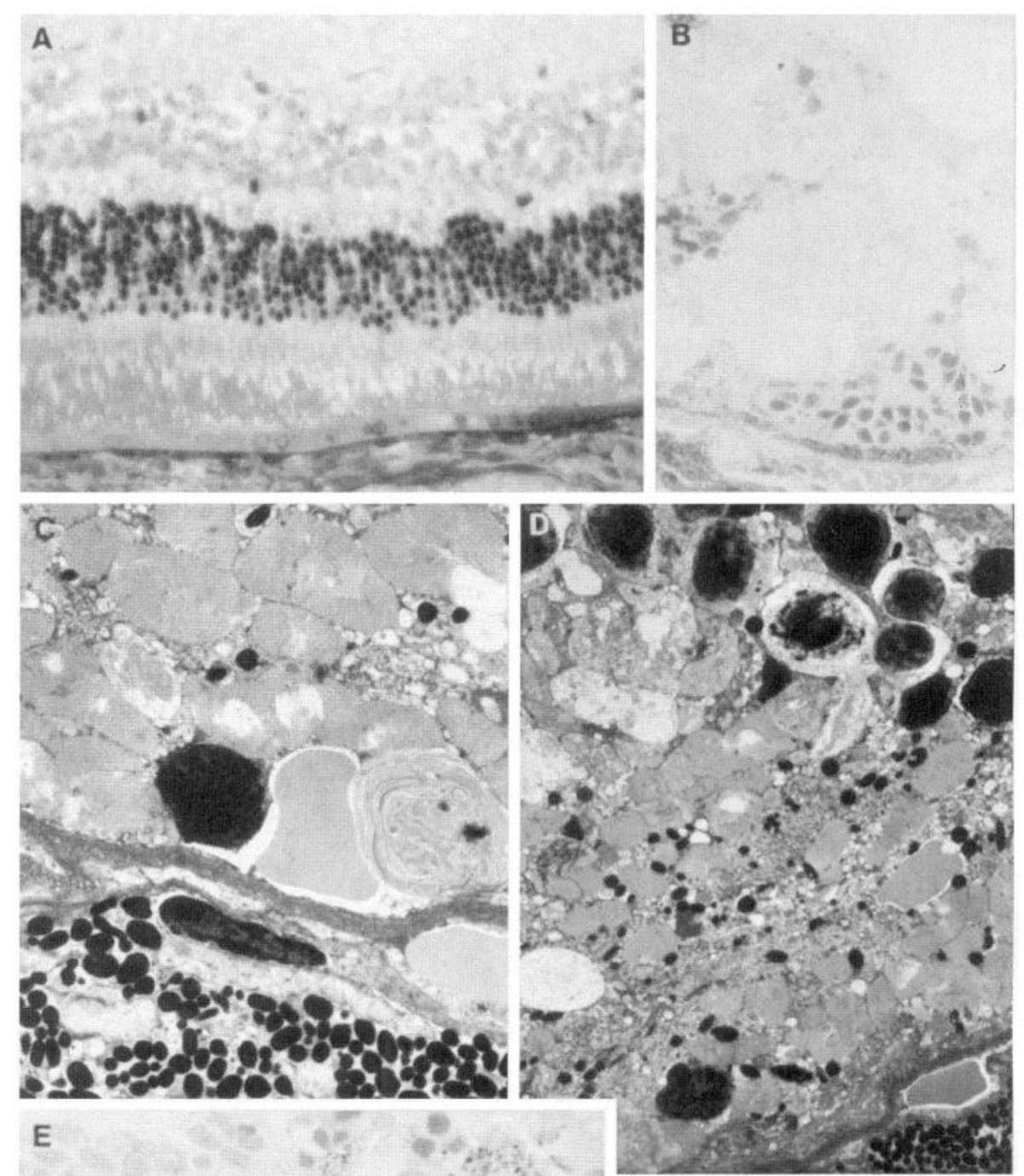

Figure 7. Slowly progressive photoreceptor degeneration in bek-6 transgenic mice. $A$, Retina from a 3-month-old $b e k-6$ mouse showing mildly abnormal outer segments $(\times 325)$. $B$, Retina from a 5 -month-old bek-6 mouse showing a region where there is loss of inner and outer segments and irregular destruction of the outer and inner nuclear layers $(\times 625)$. $C$, Transmission electron microscopy of the outer retina of a 5-month-old bek-6 mouse showing debris and disrupted outer segments adjacent to Bruch's membrane; the RPE is absent $(\times 5000) . D$, Another area in the retina of the same 5-month-old bek-6 mouse in $C$ shows severely damaged outer segments and amorphous debris sitting on Bruch's membrane with no RPE $(\times 2700)$. E, Retina from a 2-month-old bek-9 mouse showing loss of inner and outer segments and a severely damaged outer nuclear layer $(\times 625) . F$, Electron microscopy of a 2-month-old bek-18 mouse shows severely damaged outer segments mostly replaced by debris. There is neovascularization within the RPE (arrowheads) and red blood cells (arrows) among the damaged outer segments $(\times 2700)$. $G$, Fragmented chromatin in the nuclei of dead cells in the outer nuclear layer of a 2-month-old bek-18 mouse $(\times 2700)$.
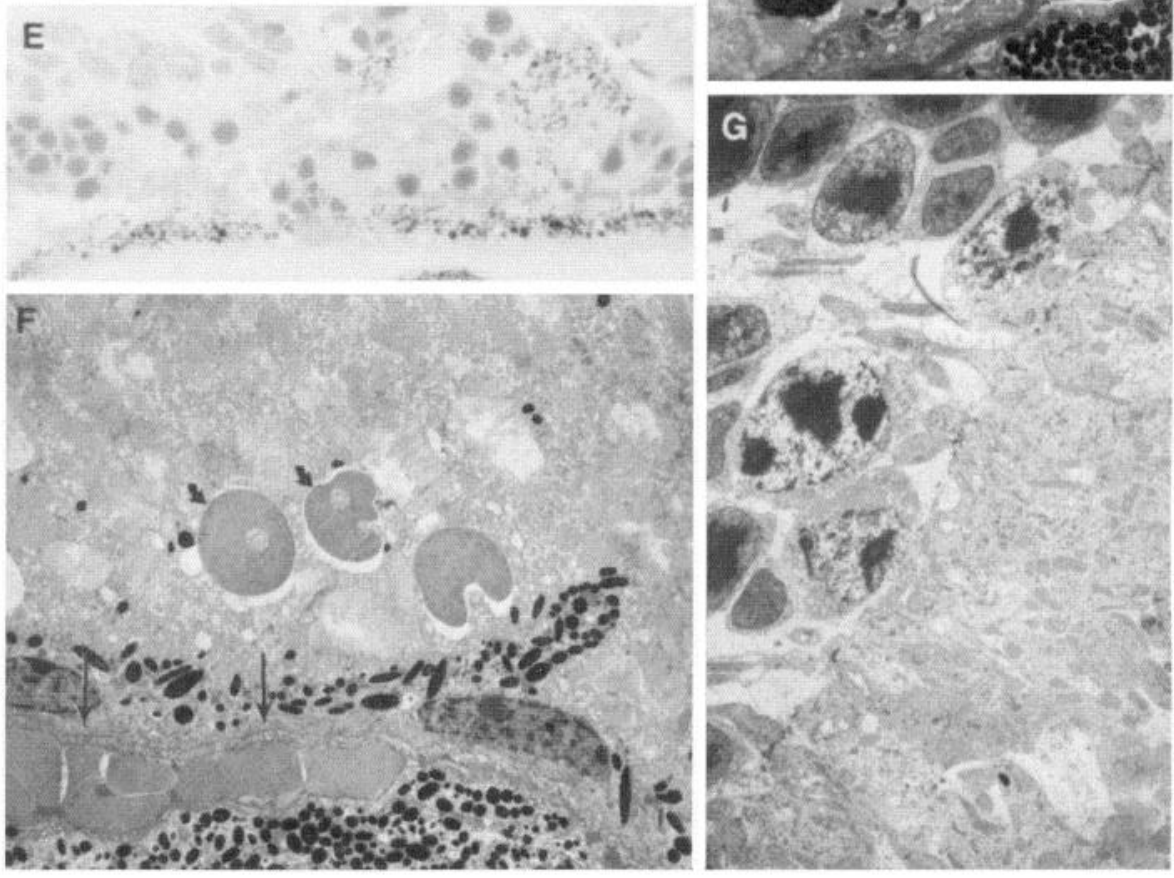


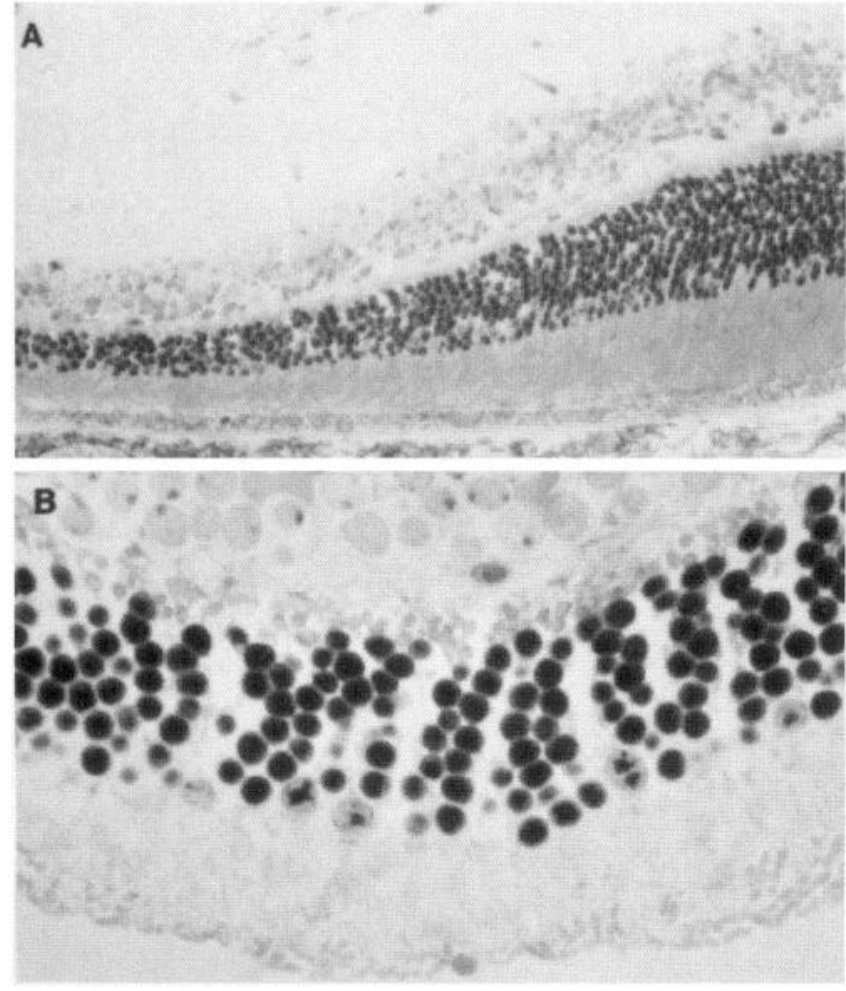

Figure 8. Flg mice show only minimal retinal changes. $A$, Regional thinning of the outer nuclear layer in a 2 -month-old flg-23 mouse. $B$, The retina of a 5-month-old flg-12 mouse shows numerous dead cells with fragmented chromatin along the outer edge of the outer nuclear layer ( $\times 625$; toluidine blue).

\section{REFERENCES}

Amaya E, Musci TJ, Kirschner MW (1991) Expression of a dominant negative mutant of the FGF receptor disrupts mesoderm formation in Xenopus embryos. Cell 66:257-270.

Anderson KJ, Dam D, Lee S, Cotman CW (1988) Basic fibroblast growth factor prevents death of lesioned cholinergic neurons in vivo. Nature 332:360-361.

Baudouin C, Fred-Reygrobellet D, Carvelle J-P, Barritault D, Gastaud P, Lapalus P (1990) Acidic fibroblast growth factor distribution in normal human eye and possible implications in ocular pathogenesis. Ophthalmic Res 22:73-81.

Blanks JC, Bok D (1977) An autoradiographic analysis of postnatal cell proliferation in the normal and degenerative mouse retina. J Comp Neurol 174:317-327.

Burns MS, Tyler NK (1990) Selective neovascularization of the retinal pigment epithelium in rat photoreceptor degeneration in vivo. Curr Eye Res 9:1061-1075.

Bush RA, Williams TP (1991) The effect of unilateral optic nerve section on retinal light damage in rats. Exp Eye Res 52:139-153.

Campochiaro PA, Hackett SF (1993) Corneal endothelial cell matrix promotes expression of differentiated features of retinal pigmented epithelial cells: implication of laminin and basic fibroblast growth factor as active components. Exp Eye Res 57:539-547.

Campochiaro PA, Hackett SF, Vinores SA, Freund J, Csaky C, LaRochelle W, Henderer J, Johnson M, Rodriguez IR, Friedman Z, Derevjanik N, Dooner J (1994) Platelet-derived growth factor is an autocrine growth stimulator in retinal pigmented epithelial cells. J Cell Sci 107:2459-2469.

Chomczynski P, Sacchi N (1987) Single-step method of RNA isolation by acid guanidinium thiocyanate-phenol-chloroform extraction. Anal Biochem 162:156-159.

Connolly SE, Hjelmeland LM, LaVail MM (1992) Immunohistochemical localization of basic fibroblast growth factor in mature and developing retinas of normal and RCS rats. Curr Eye Res 11:1005-1017.

D'Amore PA (1994) Mechanisms of retinal and choroidal neovascularization. Invest Ophthalmol Vis Sci 35:3974-3979.
Deng C-X, Wynshaw BA, Shen MM, Daugherty C, Ornitz DM, Leder P (1994) Murine FGFR-1 is required for early postimplantation growth and axial organization. Genes Dev 8:3045-3057.

Faktorovich EG, Steinberg RH, Yasumura D, Matthes MT, LaVail MM (1990) Photoreceptor degeneration in inherited retinal dystrophy delayed by basic fibroblast growth factor. Nature 347:83-86.

Freese A, Finklestein SP, DiFiglia M (1992) Basic fibroblast growth factor protects striatal neurons in vitro from NMDA-receptor mediated excitotoxicity. Brain Res 575:351-355.

Gao H, Hollyfield JG (1992) Basic fibroblast growth factor (bFGF) immunolocalization in the rodent outer retina demonstrated with an anti-rodent bFGF antibody. Brain Res 585:355-360.

Gouras P, Kjeldbye H, Zack DJ (1994) Reporter gene expression in cones in transgenic mice carrying bovine rhodopsin promoter/lacZ transgenes. Vis Neurosci 11:1227-1231.

Guillemot F, Cepko CL (1992) Retinal fate and ganglion cell differentiation are potentiated by acidic FGF in an in vitro assay of early retinal development. Development 114:745-754.

Hicks D, Courtois Y (1992) Fibroblast growth factor stimulates photoreceptor differentiation in vitro. J Neurosci 12:2022-2033.

Hogan B, Constantini F, Lacy E (1986) Manipulating the mouse genome: a laboratory approach. Cold Spring Harbor, NY: Cold Spring Harbor Laboratory.

Johnson DE, Williams LT (1993) Structural and functional diversity in the FGF receptor multigene family. Adv Cancer Res 60:1-41.

Kitaoka T, Aotaki-Keen AE, Hjelmeland LM (1994) Distribution of FGF-5 in the rhesus macaque retina. Invest Ophthalmol Vis Sci 35: 3189-3198.

Kostyk SK, D'Amore PA, Herman IM, Wagner JA (1994) Optic nerve injury alters basic fibroblast growth factor localization in retina and optic tract. J Neurosci 14:1441-1449.

LaVail MM, Unoki K, Yasumura D, Matthes MT, Yancopoulos GD, Steinberg RH (1992) Multiple growth factors, cytokines, and neurotrophins rescue photoreceptors from the damaging effects of constant light. Proc Natl Acad Sci USA 89:11249-11253.

Lem J, Applebury ML, Falk JD, Flannery JG, Simon MI (1991) Tissuespecific and developmental regulation of rod opsin chimeric genes in transgenic mice. Neuron 6:201-210.

Li Y, Basilico C, Mansukhani A (1994) Cell transformation by fibroblast growth factors can be suppressed by truncated fibroblast growth factor receptors. Mol Cell Biol 14:7660-7669.

Maiese K, Boniece I, DeMeo D, Wagner JA (1993) Peptide growth factors protect against ischemia in culture by preventing nitric oxide toxicity. J Neurosci 13:3034-3040.

Manjo G, Joris I (1995) Apoptosis, oncosis, and necrosis: an overview of cell death. Am J Pathol 146:3-15.

Mattson MP, Rydel RE, Lieberburg I, Smith SV (1993) Altered calcium signaling and neuronal injury: stroke and Alzheimer's disease as examples. Ann NY Acad Sci 679:1-21.

Nie Z, Chen S, Kumar R, Zack DJ (1996) RER, an evolutionarily conserved sequence upstream of the rhodopsin gene, has enhancer activity. J Biol Chem 271:2667-2675.

Ohuchi H, Koyama E, Myokai F, Nohno T, Shiraga F, Matsuo T, Matsuo N, Taniguchi S, Noji S (1994) Expression patterns of two fibroblast growth factor receptor genes during early chick eye development. Exp Eye Res 58:649-658.

Otto D, Unsicker K (1990) Basic FGF reverses chemical and morphological deficits in the nigrostriatal system of MPTP-treated mice. J Neurosci 10:1912-1921.

Park M, Hollenberg MJ (1989) Basic fibroblast growth factor induced retinal regeneration in vitro. Dev Biol 134:201-205.

Peters K, Werner S, Liao X, Wert S, Whitsett J, Williams L (1994) Targeted expression of a dominant negative FGF receptor blocks branching morphogenesis and epithelial differentiation of the mouse lung. EMBO J 13:3296-3301.

Pittack C, Jones M, Reh TA (1991) Basic fibroblast growth factor induces retinal pigment epithelium to generate neural retina in vitro. Development 113:577-578.

Pittler SJ, Baehr W (1991) Identification of a nonsense mutation in the rod photoreceptor cGMP phosphodiesterase $\beta$-subunit gene of the rd mouse. Proc Natl Acad Sci USA 88:8322-8326.

Ramon y Cajal S (1921) Studies on vertebrate neurogenesis [translated by Lloyd Guth (1960)], pp 144-145. Springfield, IL: Charles C. Thomas. 
Raymond PA, Barthel LK, Rounsifer ME (1992) Immunolocalization of basic fibroblast growth factor and its receptor in adult goldfish retina. Exp Neurol 115:73-78.

Schweigerer L, Malerstein B, Neufeld G, Gospodarowicz D (1987) Basic fibroblast growth factor is synthesized in cultured retinal pigment epithelial cells. Biochem Biophys Res Commun 143:934-940.

Tcheng M, Fuhrmann G, Hartmann M-P, Courtois Y, Jeanny J-C (1994) Spatial and temporal expression patterns of FGF receptor genes type 1 and type 2 in the developing chick retina. Exp Eye Res 58:351-358.

Ueno H, Colbert H, Escobedo JA, Williarns LT (1991) Inhibition of PDGF $\beta$-receptor signal transduction by coexpression of a truncated receptor. Science 252:844-847.

Ueno $H$, Gunn M, Dell K, 'I'seng Jr A, Williams L (1992) A truncated form of fibroblast growth factor receptor 1 inhibits signal transduction by multiple types of fibroblast growth factor receptor. $\mathbf{J}$ Biol Chem 267:1470-1476.

Vinores SA, Campochiaro PA, May EE, Blaydes SH (1988) Progressive ultrastructural damage and thickening of the hasement of the retinal pigment epithelium in spontaneously diabetic BB rats. Exp Eye Res 46:545-558.

Wagner M, Perry RP (1985) Characterization of the multigene family encoding the mouse S16 ribosomal protein: strategy for distinguishing an expressed gene from its processed pseudogene counterparts by an analysis of total genomic DNA. Mol Cell Biol 5:3560-3576.

Werner S, Weinberg W, I iao X, Peters KG, Blassing M, Yuspa SH Weiner RL, Williams LT (1993) Targeted expression of dominantnegative FGF receptor mutant in the epidermis of transgenic mice reveals a role of FGF in keratinocyte organization and differentiation. EMBO J 12:2635-2643.

Wyllie AH, Kerr JFR, Currie AR (1980) Cell death: the significance of apoptosis. Int Rev Cytol 68:251-306.

Yamada K, Sakaguchi T, Yuguchi T, Kohmura E, Otsuki H, Koyama T, Hayakawa T (1994) Blood-borne macromolecule induces FGF receptor gene expression after focal ischemia. Acta Neurochir (Wien) [Suppl] 60:261-264.

Yamaguchi TP, Harpal K, Henkemeyer M, Rossant J (1994) FGFR-1 is required for embryonic growth and mesodermal patterning during mouse gastrulation. Genes Dev 8:3032-3044.

Zack DJ, Bennett J, Wang Y, Davenport C, Klaunberg B, Gearhart J, Nathans J (1991) Unusual topography of bovine rhodopsin promoterlac $Z$ fusion gene expression in transgenic mouse retinas. Neuron 6 : 187-199. 